\title{
Correspondance
}

\section{Excluding the experts?}

$\mathrm{A}$ lthough it is a laudatory objective to publish only articles by authors who have no financial relationship with corporations or the products and issues discussed in the articles, as outlined in a recent $C M A 7$ editorial, ${ }^{1}$ it may not be beneficial for readers to be deprived of the information thus excluded. Furthermore, the new CMAf policy on conflict of interest guarantees that, no matter how carefully and without bias a drug company studies its product, the report of such a study will never appear in the journal. However, journals like $C M A \mathcal{A}$ are only too willing to criticize drug companies for not publishing drug studies, accusing them of trying to hide information.

Because of my unusual academic background and interests, I serve (or have served) as a paid consultant for almost every company that manufactures or sells ophthalmic viscosurgical devices, as well as the Canadian government and the US Food and Drug Administration. I sat on the International Organization for Standardization (ISO) committee that set the world standard for ophthalmic viscosurgical devices. ${ }^{2}$ I have published over 200 peer-reviewed articles, most dealing with these devices, and I am on the editorial boards of 3 ophthalmic journals. In this capacity, I review a significant proportion of the major articles about ophthalmic viscosurgical devices before they appear in the medical literature.

Like other medical editors and reviewers, I am extremely careful to avoid any possible bias in my own articles and in my reviews of articles by other researchers. I consult for all sides on most issues; I do not care who wins an argument from the financial point of view, but I do care passionately that the academic issues are resolved honestly and correctly. Undoubtedly there are many other "experts" like me, who will henceforth be excluded from contributing to your journal.

Your opinion of the ability of your readers to distinguish good articles from bad (as suggested by this policy) seems rather insulting. I am unaware of any example where censorship benefited the reader, and the new $C M A \mathcal{A}$ policy appears to be nothing less than misguided blanket censorship.

\section{Steve Arshinoff}

York Finch Eye Associates

Toronto, Ont.

\section{References \\ 1. Conflicts of interests and investments [editorial]. CMAF 2004;171(11):1313. \\ 2. Ophthalmic implants - ophthalmic viscosurgi- cal devices. ISO standard 15798:2001. Geneva: International Organization for Standardization; 2001.}

DOI:10.1503/cmaj.1050003

\section{[One of CMAJ's deputy editors responds:]}

C teve Arshinoff is concerned that $\checkmark$ CMAF's new conflict of interest policy $^{1}$ will censor legitimate science from the journal. This is certainly not the intention of the policy, which does not apply to original research papers but is restricted to narrative review articles and commentaries. The editors are well aware that companies producing drugs and medical devices frequently conduct research and fund clinical trials; the resultant papers will continue to be considered and published in the journal on the basis of their scientific merit.

Commentaries and narrative reviews, on the other hand, do not follow protocols and are inherently prone to bias. Arshinoff suggests that authors who receive a substantial income from drug companies can maintain their objectivity. His own case in this regard notwithstanding, there is ample evidence that many physicians who receive income or gifts from drug companies are indeed influenced and are more likely to hold favourable views of the products of those companies than might otherwise be the case. ${ }^{2,3}$

Readers also understand that financial conflicts of interest can challenge authors' objectivity. Given that the information published in the journal is used by our readers to practise medicine, that patient care is at stake and that public trust in physicians understandably erodes when drug companies influence the care that physicians provide, the editors feel a responsibility to safeguard the highest possible level of objectivity in those pages of the journal most directly devoted to the practice of medicine.

\section{Stephen Choi \\ Deputy Editor CMAF \\ References \\ 1. Conflicts of interests and investments [editorial] CMAf 2004;171(11):1313. \\ 2. Wazana A. Physicians and the pharmaceutical industry: Is a gift ever just a gift? $7 A M A 2000$; 283:373-80. \\ 3. Stelfox HT, Chua G, O'Rourke K, Detsky AS Conflict of interest in the debate over calcium- channel antagonists. N Engl 7 Med 1998;338(2): 101-6.}

DOI:10.1503/cmaj.1050192

\section{The marginalization of some medical students}

T 7 e very much appreciate Verna $\checkmark$ Yiu's recent article on the wellbeing of medical students and the enormous level of stress we face. ${ }^{1}$ It is very important for medical schools not to overlook the psychosocial health of the future physician workforce.

Students from marginalized populations, such as gay, lesbian, bisexual and transgendered (GLBT) medical trainees, face additional sources of stress that go beyond the "normal stressors of everyday life." They have to contend with prejudice from others in the medical community; $;^{2-4}$ the medical profession has traditionally been more conservative than many other fields.

GLBT medical trainees are still being marginalized in the profession. ${ }^{5-9}$ Hateful jokes and disrespectful attitudes from peers and superiors make it difficult for GLBT students to relate to others in the social and professional settings of medical schools, thereby putting additional strains on their working rela- 
tionships and career choice decisions. ${ }^{2,4,67}$ Also, because of their sexual orientation, GLBT students and residents are often the targets of unprofessional behaviours, such as harassment and academic mistreatment, from their supervisors and faculty members. ${ }^{9,10}$

Although Canadian medical schools have been proactive in supporting other underrepresented groups in the profession, such as women and Aboriginal medical students, more work is needed to address the needs of GLBT medical students.

\section{Louie Chan}

Medical student, Class of 2007

University of Toronto

Toronto, Ont.

Shelley Turner

Medical student, Class of 2006

McMaster University

Hamilton, Ont.

\section{References}

1. Yiu V. Supporting the well-being of medical students. CMA7 2005;172(7):889-90.

2. Risdon C, Cook D, Willms D. Gay and lesbian physicians in training: a qualitative study. CMAJ 2000;162(3):331-4.

3. Stefan M. GLMA conference stresses tolerance, sensitivity toward sexual minorities. Ont Med Rev 2000;67(1):57.

4. Peterkin A, Rison C. Caring for lesbian and gay people: a clinical guide. Toronto: University of Toronto Press; 2003. p. 1-24, 291-308.

5. Moulton D. ACMC: Study looks at med students' views of gays. Med Post 2004;40(19):16.

6. British Medical Association. Career barriers in medicine: doctors' experiences. London (UK): The Association; 2004.

7. Burke BP, White JC. Wellbeing of gay, lesbian, and bisexual doctors. BM7 2001;322(7283): 422-5.

8. Klamen D, Groosman L, Kopacz D. Medical student homophobia. 7 Homosex 1999;37(1):53-63.

9. Brogan DJ, Frank E, Elon L, Sivanesan SP, O'Hanlon KA. Harassment of lesbians as medical students and physicians. FAMA 1999;282 (13):1290-2.

10. Peterkin AD. Staying buman during residency training. 3rd ed. Toronto: University of Toronto Press; 2003. p. 99-105.

DOI:10.1503/cmaj.1050112

$\mathrm{I}$ thank Louie Chan and Shelley Turner for their comments, in response to my recent $C M A 7$ piece, ${ }^{1}$ on a very important issue that faces GLBT medical students. I agree with them that medical schools across Canada need to be more proactive on this subject.

At the University of Alberta we are trying to address GLBT issues in sev- eral ways. The first was through an educational session on GLBT issues with our student advisors. We are hoping to integrate diversity modules into our medical curriculum and are developing a support group for staff, residents and medical students who are dealing with GLBT issues within our medical school. In 2004 I attended a conference of the Canadian Rainbow Health Coalition (a national organization that provides a means for people working on GLBT health and wellness issues to network and advocate together) and tried to network that organization with the Association of Faculties of Medicine of Canada. The Coalition is also developing educational materials that I hope can be used in the medical curriculum.

Although there is a long road ahead to completely change the attitudes of people within the medical field, I am hopeful that continued small advances will eventually lead to a safe and healthy environment for all minority medical student groups.

\section{Verna Yiu}

Assistant Dean, Student Affairs

Faculty of Medicine and Dentistry

University of Alberta

Edmonton, Alta.

\section{Reference}

1. Yiu V. Supporting the well-being of medical students [editorial]. CMA7 2005;172(7):889-90.

DOI:10.1503/cmaj.1050146

\section{An unusual crystal}

$\mathrm{W}$ e were most interested in the report by Joe Dylewski and colleagues on acute monoarticular arthritis caused by birefringent Maltese cross-like crystals composed of lipids. ${ }^{1}$ Arthritis has been reported in patients with hyperlipidemias, especially type II. ${ }^{2}$ Although Glueck and colleagues ${ }^{3}$ reported synovitis in such patients, the body of evidence favours a periarticular site of inflammation. ${ }^{4}$ Cholesterol crystals have been identified in some patients but do not appear to be particularly inflammatory. ${ }^{5}$ To date we know of no other report of
Maltese cross-like crystals in patients with arthritis associated with hyperlipoproteinemia.

Why arthritis is associated with hyperlipoproteinemia remains a mystery. Perhaps high levels of blood blood lipids of a certain type act as a source of lipid-bound macroenzymes. ${ }^{6}$ It is perhaps germane that high concentrations of trypsin and lipase resulting from pancreatic disease cause synovial fat necrosis with either a mono- or polyarthritis and subcutaneous necrosis. ${ }^{7,8}$

\section{W. Watson Buchanan}

Emeritus Professor of Medicine

Walter F. Kean

Clinical Professor of Medicine

McMaster University

Head of Service, Rheumatology

Hamilton Health Sciences

Hamilton, Ont.

\section{References}

1. Dylewski J, Awan Z, Roy, I. Acute monoarticular arthritis caused by Maltese cross-like crystals. CMA7 2005;172(6):741-2

2. Rifkind BM. The hyperlipoproteinaemias. $B \mathcal{F}$ Hosp Med 1970;4:683-92.

3. Glueck EJ, Levy RI, Frederickson DS. Acute tendinitis and arthritis. A presenting symptoms of familial type II hyperlipoproteinemia. $7 A M A$ 1968;13:2895-7.

4. Struthers GR, Scott DL, Bacon PA, Walton KW. Musculoskeletal disorders in patients with hyperlipideamia. Ann Rheum Dis 1983;42:519-23.

5. Fam AG, Sugai M, Gertner E, Lewis A. Cholesterol "tophus." Arthritis Rheum 1983;26:1525-8.

6. Remaley AT, Wilding P. Macroenzyems: biochemical characterization, clinical significance, and laboratory detection. Clin Chem 1989;35:2261-70.

7. Hughes PSH, Apisarnthanrax P, Mullins JF. Subcutaneous fat necrosis associated with pancreatic disease. Arch Dermatol 1975;111:506-10.

8. Smuckler NM, Schumacher HR, Pascual E, Brown S, Ryan WE, Sadeghian MR. Synovial fat necrosis associated with ischemic pancreatic disease. Arthritis Rheum 1979;22(5):547-53.

DOI:10.1503/cmaj.1050126

W e appreciate the interest shown by Drs. Buchanan and Kean in our case. ${ }^{1}$ As mentioned in the text, elevated levels of lipids in the serum and/or synovial fluid are unusual in Maltese-cross crystal-associated arthritis (only 2 of 13 reported cases). The references cited in our text suggest that the lipid-containing crystals are formed in the synovial fluid by various proposed but unproven mechanisms. They are not the product of an abnormal 